\title{
Dislocations in French-English bilingual children: an elicitation study
}

Article

Accepted Version

Herve, C., Serratrice, L. and Corley, M. (2016) Dislocations in French-English bilingual children: an elicitation study.

Bilingualism: Language and Cognition, 19 (5). pp. 987-1000. ISSN 1469-1841 doi:

https://doi.org/10.1017/S1366728915000401 Available at https://centaur.reading.ac.uk/66494/

It is advisable to refer to the publisher's version if you intend to cite from the work. See Guidance on citing.

To link to this article DOI: http://dx.doi.org/10.1017/S1366728915000401

Publisher: Cambridge University Press

All outputs in CentAUR are protected by Intellectual Property Rights law, including copyright law. Copyright and IPR is retained by the creators or other copyright holders. Terms and conditions for use of this material are defined in the End User Agreement.

\section{www.reading.ac.uk/centaur}

\section{CentAUR}

Central Archive at the University of Reading 
Reading's research outputs online 
Highlights

- Frequency matters in bilinguals' and monolinguals' use of LDs in French and English.

- In English, the sub-optimal nature of LDs reinforced the resistance to LD primes.

- Exposure to French increased the probability of producing LDs after LD primes in both English and French.

- Language exposure and the processing of high frequency constructions affect CLI. 
Dislocations in French-English bilingual children: An elicitation study*

Coralie Hervé $^{12}$, Ludovica Serratrice ${ }^{2} \&$ Martin Corley $^{3}$

Université Paris Diderot - Paris $7^{1}$

University of Manchester ${ }^{2}$

University of Edinburgh ${ }^{3}$

(*) Acknowledgments: we gratefully acknowledge the staff and children at Collège Bilingue Français de Londres, La Petite Ecole Bilingue (London and Paris), L'Ermitage (Paris), Beaver School (Manchester) and L'Ecole Maternelle rue Saint-Jacques (Paris) for their enthusiastic collaboration.

Address for correspondance:

Dr Ludovica Serratrice

The University of Manchester

School of Psychological Sciences

Coupland 1 Building

Oxford Road

Manchester M13 9PL

Email: serratrice@manchester.ac.uk 


\begin{abstract}
This paper presents the results of two sentence production studies addressing the role of prior linguistic modelling, discourse-pragmatic appropriateness and language exposure on the phenomenon of cross-linguistic influence (CLI) in bilingual 5-year-olds. We investigated whether French-English bilingual children would be as likely as monolingual children to use a left-dislocation structure in the description of a target scene. We also examined whether input quantity played a role on the degree of accessibility of these syntactic constructions across languages. While the results indicate a significant effect of elicitation condition only in French, amount of exposure to French predicted the likelihood of producing a left-dislocation in both French and English. These findings make a new contribution to the role of language exposure as a predictor of CLI. The data also support the recent proposal that CLI arises out of processing mechanisms.
\end{abstract}

Keywords: bilingual first language acquisition, cross-linguistic influence, language processing, discourse-pragmatics 


\section{CLI: input quantity and language processing}

One of the central questions in bilingual language development research over the last fifteen years has been the issue of cross-linguistic influence (CLI), i.e. the extent to which, and under what circumstances, the two languages of a bilingual child interact and give rise to linguistic behaviours that are quantitatively and/or qualitatively different from those of monolingual children. Hulk \& Müller (2000) were the first to formulate specific predictions about CLI, although Döpke (1998) had already flagged the issue in a previous study of word order in English-German bilingual children. Hulk \& Müller's (2000) seminal hypothesis was that CLI occurs in bilingual children if (a) the structure in question is at the interface between two modules of grammar, and more specifically at the interface between discoursepragmatics and syntax in the so-called C-domain, and if (b) there is a degree of overlap between the two language systems at the surface level (Hulk \& Müller, 2000: 228-229). Since then, evidence of CLI occurring even after the instantiation of the C-domain has been reported for the realization of pronominal arguments especially in null-subject and non-nullsubject language pairs (Paradis \& Navarro, 2003; Serratrice, Sorace, \& Paoli, 2004; Sorace, Serratrice, Filiaci, \& Baldo, 2009). Recently cross-linguistic effects have also been observed at the clause level for structures such as compound nouns in Persian and English (ForoodiNejad \& Paradis, 2009), Noun+Adj strings in French and English (Nicoladis, 2006) and passive structures in Spanish and English (Vasilyeva, Waterfall, Gámez, Gómez, Bowers, \& Shimpi 2010). Capitalizing on Hulk \& Müller's (2000) early work, subsequent research started examining additional predictors of CLI including factors such as language dominance, processing mechanisms, input quality and age. The present study specifically focuses on whether CLI is affected by prior linguistic processing and amount of language exposure. 


\section{Input quantity}

Input effects in bilingual acquisition have been observed on bilingual children's language development, particularly for the acquisition of morpho-syntax and the lexicon (Barnes \& Garcia, 2013; Hoff et al., 2012; Paradis, 2011; Thordardottir, 2011) but also phonology (Nicoladis \& Paradis, 2011; Sundara \& Scutellaro, 2011).

A growing body of research has started to investigate the impact of input quantity on CLI, although so far only very general measures of language exposure, such as the language of the environment, have been considered (Argyri \& Sorace, 2007; Serratrice, Sorace, Filiaci, \& Baldo, 2009, 2011; but see Kidd, Chan \& Chiu, 2014, for a recent exploration of language exposure at the level of the individual). In these studies, the role of input quantity on CLI was assessed by assuming that bilingual children would have greater exposure to the language of the community, and the results did show a general effect of the language of the environment on CLI, among other variables. Argyri \& Sorace (2007) reported different results while comparing two groups of 8-year-old Greek-English bilinguals growing up in Greece and in the UK. Only the children living in the UK, hence categorised as dominant in English, displayed CLI from English to Greek in the acceptance and use of non-target pre-verbal subjects in wide focus contexts (1) and non-target pre-verbal subjects in what-embedded interrogatives in Greek (2). Language of the community, as a proxy for language dominance, was one of the variables affecting the degree of CLI.

(1) Question: Ti ejine to molivi tis Marias?

What happen's to Maria's pencil?

Puppet: A (preverbal.subj): ${ }^{*} \mathrm{I}$ Hara to pire.

The Hara-NOM it-CL took-3SG

'Hara took it'. 
(Argyri \& Sorace, 2007: 89)

(2) Puppet A (postv.subj.): Den thimate [ti efage $i$ Maria]. not remember-3SG what ate-3SG the Maria-NOM "She doesn't remember what Maria ate."

Puppet B (prev.subj.): $\quad{ }^{*}$ Den thimate $\quad[$ ti $\quad$ i Maria $\quad$ efage $]$. not remember-3SG what the Maria-NOM ate-3SG “She doesn't remember what Maria ate."

(Argyri \& Sorace, 2007: 90)

Similar results were observed by Serratrice et al.'s (2009) study on 6- to 10-year-old Italian-English and Spanish-Italian children's encoding of specificity and genericity in plural noun phrases. The English-Italian bilingual children accepted significantly more ungrammatical bare nouns in generic contexts in Italian, as in (3), than all the other groups. Crucially, the bilinguals living in the UK performed less accurately in Italian than the bilinguals in Italy. The children's limited exposure to Italian had an effect on their acceptance of bare nouns in generic context in this language.
(3) * In genere squali sono pericolosi.
(ungrammatical generic) in general sharks are dangerous "In general sharks are dangerous."

(Serratrice et al, 2009: 246) 
Along the same lines, Serratrice et al. (2011) also observed an effect of the language of the environment on CLI in a study examining 6- to 10-year-old English-Italian and Spanish-Italian children's knowledge of pronominal objects. The English-Italian children in the UK accepted infelicitous postverbal object pronouns in [- focus] contexts as in (4) twice as often as the Italian monolingual children and more often that all other bilingual groups.

(4) Voice over: Che cosa ha fatto Minnie a Paperina?

"What has Minnie done to Daisy?"

Scrooge: Ha abbracciato lei. (Pragmatically inappropriate)

$\square$ “(She) has hugged her."

(Serratrice et al, 2011: 12)

The common denominator of these studies investigating the role of language exposure is the assumption that the bilinguals would be predominantly exposed to the language of their living environment. This is however not uncontroversial; one of the reasons the studies reviewed here found an overall effect of the language of the community is because they were considering older school-age children for whom we can assume that the language of the community plays a more significant role in their daily interactions than the minority home language. In the case of pre-school children, who may be spending more time at home with a minority language-speaking parent or other minority language-speaking caregivers, making the same assumption is potentially more problematic as the role of the community in the child's daily language input would be considerably more restricted than for older children. Therefore, research investigating the role of input quantity on CLI should always include an independent measure of language exposure, especially in the case of younger children for whom relative exposure to the two languages cannot be straightforwardly inferred from their 
environment. A measure of language exposure could then be used as a quantitative predictor of the likelihood of CLI (see Unsworth, 2013 ; 2014 for a recently developed tool assessing current and cumulative exposure).

The role of individual language exposure as a predictor of CLI is yet underinvestigated, but there is now a large and expanding body of literature on the role of input quantity and quality in bilingual development. A positive correlation has repeatedly been reported between amount of language exposure and language proficiency in lexical development (Marchman \& Martínez-Sussman, 2002; Patterson, 2002), onset of combinatorial speech (Hoff, Core, Place, Rumiche, Senor \& Parra, 2012; Marchman, Martinez-Sussman \& Dale, 2004); and various aspects of grammatical development (Blom, 2010; Gathercole, 2007). At the same time some studies have shown that there is not always a straightforward relationship between input quantity and proficiency. Two recent vocabulary studies with French-English Canadian children (Smithson, Paradis \& Nicoladis, 2014; Thordardottir, 2011) did not find the often reported differences with monolingual peers for some groups of bilinguals (pre-schoolers), and for some aspects of expressive vocabulary. With respect to morphological acquisition Paradis, Nicoladis, Crago \& Genesee (2011) showed that the acquisition rate of French regular past tense in French-dominant FrenchEnglish bilingual four-year-olds was not significantly different from that of monolingual peers despite the bilinguals' reduced amount of exposure to French.

\section{Processing and shared syntactic representations}

Research on bilingual development has also started to investigate whether the daily processing of two languages affects the rate of bilingual development (i.e. acceleration, delay) and the bilingual children's use of their languages (i.e. transfer) (Nicoladis, Rose, \& Foursha-Stevenson, 2010; Sorace \& Serratrice, 2009). Specifically, a growing body of 
evidence suggests that the additional processing demands caused by the simultaneous acquisition of two languages would be responsible for delays in the development of grammatical structures or cross-linguistic transfer (Nicoladis, 2006, 2012; Pirvulescu, PérezLeroux, \& Roberge, 2012; Pirvulescu, Pérez-Leroux, Roberge, Strik, Thomas, 2014; Serratrice et al., 2011; Sorace et al., 2009).

Recently, studies adopting the structural priming paradigm have contributed to the study of syntactic representations in bilingual adults and children. The structural, or syntactic, priming methodology is based on speakers' tendency to repeat the syntactic structures they have recently been exposed to (Bock, 1986). Observing people's sensitivity to primed expressions provides information on the nature of syntactic representation (Branigan, 2007:

1). While syntactic priming has been used extensively with monolingual adults and increasingly with children (Kidd, 2012; Savage, Lieven, Theakston, \& Tomasello, 2003, 2006; Shimpi, Gámez, Huttenlocher, \& Vasilyeva, 2007; Thothathiri \& Snedeker, 2008), relatively few studies have used this paradigm to examine the issue of shared syntactic representations in bilinguals and to explore a processing account of CLI. So far, these few studies have mainly focused on proficient adult speakers of an L2 (Hartsuiker, Pickering, \& Veltkamp, 2004; Schoonbaert, Hartsuiker, \& Pickering, 2007). Experiments on advanced adult second language learners (Desmet \& Declercq, 2006; Hartsuiker et al., 2004; Loebell \& Bock, 2003; Schoonbaert et al., 2007) have provided evidence of structural priming across languages (from L1 to L2 or from L2 to L1) suggesting that bilingual adults share syntactic representations across languages for certain structures such as passive or ditransitive constructions that exist in their two languages.

Vasilyeva et al. (2010) conducted the first structural priming experiment with Spanish-English bilingual 5-year-olds. Following Hartsuiker et al.'s (2004) design, the children were primed with passive or active structures across languages (i.e. Spanish to 
English or English to Spanish). The results did show a significant cross-linguistic priming effect, but this effect was unidirectional from Spanish to English. When primed with Spanish fue-passive sentences, the children increased their use of passive constructions in English. However, the reverse effect was not observed; exposure to English passives in the prime sentences did not lead to a significant increase of fue-passives in Spanish. The fact that priming from English to Spanish was not successful is somewhat problematic. Although the study did not include independent measures of language proficiency or of language exposure, the authors concluded, on the basis of an analysis of the level of syntactic mastery in the children's responses to the experiment, that there was not a substantial difference across their two languages to justify the asymmetry of the results. Instead they proposed that the relative infrequency of the fue-passive construction in Spanish was responsible for the lack of priming after exposure to English passives.

In another cross-linguistic syntactic priming experiment on bilingual children Hsin, Legendre \& Omaki (2013) set out to test whether grammatical structures are represented in a language-independent format so that all syntactic structures are available in both languages regardless of their language-specific realization. Hsin et al. (2013) showed that SpanishEnglish five-year-olds could be primed to use the (largely unattested) Adj-N word order in Spanish in a target picture description after hearing an English prime containing the canonical English Adj-N word order. They also included a baseline elicitation condition with no prime, and a neutral condition where the target picture description in Spanish was preceded by an English sentence containing an adjective embedded in a relative clause; in both of these conditions the proportion of Adj-N responses was significantly lower than in the priming condition. The authors also reported a marginal correlation between language dominance, as measured by standardized tests of receptive vocabulary, and the use of the Adj-N order in the elicitation condition; they also found a strong correlation between these variables in the 
neutral condition. However, the authors did not observe any significant correlation between language dominance and the use of Adj-N strings in the priming condition. Language dominance, as measured by the children's receptive vocabulary, did not account for their use of the infelicitous Adj-N order in Spanish. Overall, this study suggests that bilingual children's mental representation of syntactic structures is shared across languages regardless of whether they present a case of structural overlap. It also indicates that language dominance measured in terms of receptive vocabulary alone is not a predictor of CLI.

In summary, syntactic priming has been successfully used to explore the issue of shared syntactic representations in bilingual adults. Vasilyeva et al.'s (2010) and Hsin et al.'s (2013) studies suggest that linguistic representations are shared across languages in bilingual children too, regardless of their availability across languages, i.e. presence vs. absence of overlap across the two languages. The findings of these studies also imply that CLI may be conceptualized in terms of cross-linguistic structural priming, on the assumption that access to structures in both languages is always available to the bilingual speaker. The routine processing of grammatical constructions in two languages may occasionally lead to interference between optimal and sub-optimal structures at the level of syntactic representation resulting in CLI. Which factors predict the likelihood and the magnitude of CLI remains unclear. Vasilyeva et al.'s (2010) findings suggest that the frequency of a construction may affect the degree of activation of this structure at the level of syntactic representation and thus the likelihood of CLI; whether the amount of exposure has any role to play in predicting the likelihood of priming is yet to be seen.

To date, structural priming in bilingual children has exclusively been tested across languages. However, within-language experiments should also be considered as bilingual children may occasionally be exposed to attrited or non-native input containing morphosyntactic constructions that would be sub-optimal from a discourse-pragmatic point of view 
(e.g. Tsimpli, Sorace, Heycock, \& Filiaci, 2004). Caregivers' prolonged contact with another language is likely to result in contact-modified input displaying sub-optimal form-function mappings (Paradis \& Navarro, 2003; Schmid, 2010); this would provide bilingual children with input containing constructions that are not discourse-pragmatically appropriate. The input availability of these constructions that are, on the one hand completely appropriate in one language (e.g. the use of pronouns in topic maintenance contexts in non-null-subject languages), and at the same time sub-optimal in the other language (e.g. the use of overt pronouns in topic maintenance contexts in null-subject languages) would make it likely that children themselves would reproduce these sub-optimal form-function mappings in their own speech. The two syntactic priming studies reviewed above have provided some evidence for the possibility that hearing a construction in language A will prime its use in language B, regardless of its grammaticality. Unlike priming experiments, the present elicitation studies consider the role of discourse-pragmatically appropriateness as well as input manipulation on the children's productions. Specifically, we ask whether bilingual children are more likely than monolingual children to use discourse-pragmatically inappropriate constructions when we consider input and output within one single language. Examining the role of pragmatically sub-optimal input would shed some light on how attrited or non-native input may affect bilingual children's use of their languages. Eliciting the production of withinlanguage target descriptions would also provide information on the extent to which children's linguistic representations are shared across languages; hearing the experimenter use a description that is sub-optimal in language A (e.g. an overt pronoun for topic-maintenance in a null-subject language like Italian), but perfectly acceptable in language B (i.e. a non-nullsubject language like English), would boost the activation of the structure and make it more likely that children would re-use it themselves when describing a target scene in language A thus producing a pragmatically inappropriate structure. 
CLI beyond pronominal realization: the expression of topicality at the sentence level in left dislocation

So far the bulk of research examining CLI at the interface between syntax and discourse-pragmatics has focused on the realization of pronominal expressions (Hacohen \& Schaeffer, 2007; Hauser-Grüdl, Arencibia Guerra, Witzmann, Leray, \& Müller, 2010; Pinto, 2006; Serratrice, 2007; see Serratrice, 2013 for a recent review). The present studies take the investigation of CLI at the interface between syntax and discourse-pragmatics beyond single referential expressions to the sentence level. We focus on the expression of topicality in two elicited production studies involving French-English bilingual children; in particular we investigate how the use of Left Dislocations (LDs) is affected by prior discourse context and by amount of language exposure.

LDs typically include a constituent that appears to the left periphery of a main clause that is co-referential with a resumptive element as in (5) in which the noun phrase le lion and the strong pronoun lui are both co-indexed with the subject clitic $i l$.

(5) Le zébre et le lion courent dans la savanne.

The zebra and the lion run in the savannah

'The zebra and the lion run in the savannah'.

Maintenant, le lion ${ }_{\mathrm{i}}$, lui, $\mathrm{il}_{\mathrm{i}} \quad$ se repose pendant que le zébre se baigne.

Now the $\operatorname{lion}_{\mathrm{i}}$, him, $_{\mathrm{i}}$ rests while the zebra REFL bathes

'The lion rests while the zebra has a bath'

LDs are an interesting test case, as they appear to be strong candidates for CLI (Hervé, 2014; Notley, van der Linden, \& Hulk, 2007). There is partial overlap in the way in 
which topicality is encoded in French and in English. LDs mark topics in both languages; however, only French strongly relies on their use as about $20 \%$ of utterances in spoken French contain a dislocation (Barnes, 1985; De Cat, 2002; Lambrecht, 1981, 2001). In English, topics are largely encoded by the canonical SV(O) word order and topic dislocation, though possible, is not at all frequent as only $1 \%$ of utterances contain one (Donaldson, 2011; Geluykens, 1992). LDs are syntactically and pragmatically less constrained in French than in English (i.e. nature of dislocated and resumptive elements, discourse functions). In both languages, about $70 \%$ of LDs are associated with the subject of the main clause (BlascoDulbecco, 1999; Snider \& Zaenen, 2006). Although a variety of grammatical elements can be dislocated, LD elements typically correspond to full NPs or strong pronouns (BlascoDulbecco, 1999; Geluykens, 1992). The fundamental difference between French and English lies in the accessibility of the LD element. In Prince's (1981) terms, LD elements are predominantly discourse old or inferable (i.e. extra-linguistic) referents in French (Barnes, 1985; Delais-Roussarie, Doetjes, \& Sleeman, 2004; Lambrecht, 2001). In contrast, LDs principally introduce discourse-new or inferable referents in English (Donaldson, 2011; Gregory \& Michaelis, 2001; Ochs-Keenan \& Schieffelin, 1976). Finally, LDs are used for a greater variety of discourse functions in French than in English.

\section{Aims of the present study and predictions}

The existence of cross-linguistic syntactic priming suggests that bilinguals share syntactic representations across languages since hearing a construction in language A primes the same construction in language B (Hartsuiker et al., 2004; Vasilyeva et al., 2010; Hsin et al., 2013). Moreover, the asymmetric relationship observed by Vasilyeva et al. suggests that cross-linguistic priming is in some way also mediated by the respective frequency of the 
target syntactic structure in the two languages and potentially by bilinguals' relative exposure to their two languages.

In the present elicitation studies, the aim was to explore children's sensitivity to the language-specific encoding of topical subjects in English and French at the sentence-level, and to investigate the role of language exposure on the likelihood of CLI. The relationship between the bilingual children's representation of topics was examined in two withinlanguage elicited production experiments, one in French (study 1) and one in English (study 2) in order to answer the following questions:

1. What is the effect of input manipulation on the probability of producing a left dislocation in French (study 1) and in English (study 2)?

2. What is the role of language exposure on the probability of producing a left dislocation in French (1) and in English (2)?

Previous research has shown that topics are obligatorily dislocated to create a topical contrast in French when they are not expressed by a weak pronoun (De Cat, 2002; Lambrecht, 1994). English favours the subject-verb order to mark topicality (Donaldson, 2011). By this rationale, high proportions of LD responses are expected in French regardless of elicitation condition. Conversely, low proportions of LDs are expected in English given their relative low frequency in the language as a whole. Nonetheless, it is anticipated that LD production will be significantly different as a function of input manipulation and context. In particular, the number of target LDs produced after the modelling of a LD in the elicitation condition should be higher than the number of those following a NP+VP (SV) description in the elicitation condition. 
Following earlier research examining the effect of input quantity on CLI (Argyri \& Sorace, 2007; Kupisch, 2007; Serratrice et al., 2011; Sorace et al., 2009), we anticipate that exposure to French will affect the magnitude of CLI since dislocations are high-frequency structures in this language. In both experiments, there should be a positive correlation between the children's exposure to French and the probability that they will produce a LD. In French, we expect all children regardless language background to use a considerable number of LDs in the LD condition. We also assume that the monolingual children and the bilingual children the most exposed to French should be maximally likely to produce LDs while the bilinguals the least exposed to French should use fewer LDs. In English, the monolingual children should be the least likely to produce LDs while the bilinguals with the highest exposure to French should be the most likely to use LDs.

Finally, we do not expect to observe a significant interaction between elicitation condition and language exposure in French due to the pervasive use of LDs in this language. Conversely, the proportion of LDs should be significantly higher in the LD condition than in the NP+VP condition in English for children with the highest amount of French exposure

\section{Methods}

\section{Participants}

A total of 78 children were recruited from six schools in the UK and in France (40 girls, 38 boys): 19 French-English children (mean age 5;5, age range 5;4-6;4) in two bilingual schools in London; 19 French-English children (mean age 5;9, age range 5;4-6;7) in two bilingual schools in the Paris area; 20 English monolingual children (mean age 6;00, age range 5;07-6;04) in a school in Manchester and 20 French monolingual children (mean age = $5 ; 9$, age range $5 ; 4-6 ; 4)$ in a school in Paris. There was no significant difference in age between the bilingual groups $(\mathrm{M}=5.9, \mathrm{SD}=3.90)$ and the French monolingual group $(\mathrm{M}=$ 
$5.95, \mathrm{SD}=3.42) ; t(52)=-0.69, p=.49)$ nor between the bilingual groups $(\mathrm{M}=5.90, \mathrm{SD}=$ 3.90) and the English monolingual group $(\mathrm{M}=6.05, \mathrm{SD}=2.37) ; t(54)=-1.04, p=.058)$. Ethical approval was obtained from the first two authors' university research ethics committee; parents were asked to sign an informed consent form.

The two bilingual groups took part in both the French and the English experiments while the English-speaking and the French-speaking monolinguals only took part in their respective language. The monolingual children were recruited in schools situated in uppermiddle class neighbourhoods in order to match the socio-economic status of the children attending the private bilingual schools. All our bilingual participants were exposed simultaneously to English and French from birth or soon after. They were either the offspring of mixed French-English couples $(\mathrm{N}=29)$, or of French couples living in the UK $(\mathrm{N}=5)$, or of English-speaking couples living in France $(\mathrm{N}=4)$. The parents were asked to report about their child's language background using Cattani, Abbot-Smith, Farag, Krott, Arreckx, Dennis, Foccia's (2014) questionnaire which provides an estimate of the child's language exposure. The questionnaire requested information about (i) the average number of hours spent by the child in the bilingual school/with a childminder; (ii) the language(s) spoken by each parent in the home; (iii) the weekly number of hours spent by the child alone with each parent; (iv) whether the parents engaged equally with their child; and (v) an evaluation of the number of hours of the child's sleep in a typical day. Following Cattani et al. (2014), we defined $60 \%$ of exposure to a language as the cut-off point for establishing the majority input language. The questionnaire data revealed very different patterns of language exposure among the children in London and in Paris. Contrary to what had been assumed in previous research (e.g. Argyri \& Sorace, 2007, Sorace et al., 2009), the children were not necessarily predominantly exposed to the language of the local environment (see Table 1). 
$<$ Insert Table 1 about here $>$

The bilingual group in Paris includes a larger number of balanced bilinguals $(\mathrm{N}=13)$ compared to the London group $(\mathrm{N}=6)$. Overall, it is in London that the bilinguals were the most dominant in French $(\mathrm{N}=9)$. Across the two groups, there is nearly the same number of English dominant children (Paris $\mathrm{N}=3$; London $\mathrm{N}=4$ ). Finally, the children recruited in the monolingual schools in Paris and in London were strictly monolinguals.

\section{Materials and design}

For each experiment, we had two elicitation conditions: LD and NP+VP in which the children heard a prompt that contained either LDs or NP+VP (SV) to describe a scene. The materials consisted of 40 sets of pictures for the French and for the English experiment respectively, 20 for each elicitation condition (NP+VP, Left Dislocation). The picture sets were based on popular children's cartoons such as Rio, and Dora the Explorer for the French study, and on Madagascar and Toy Story 3 for the English study. Different cartoons were used for each condition in order to ensure we would have a sufficient number of different picture sets in all the testing conditions. The pictures consisted of screenshots of these films and were compiled into PowerPoint presentations. Each picture was only used once.

In order to create a target context in which the pragmatically appropriate form to identify a referent would be a LD, we followed De Cat's (2009) experimental design. The first picture of each set created a discourse-pragmatic context in which two animate referents engaged in the same action were introduced and established as topics by the use of a LD (6.a). The description was followed by a prompt question containing a LD that maintained the topical status of the referents (6.b) ${ }^{1}$. The target picture to be described by the child reintroduced the two topical referents side by side but engaged in two different actions (6.c). 
This set-up was designed to elicit a topical contrast requiring a LD in spoken French as the two previously mentioned referents needed to be distinguished from each other.

(6) a. Blue et Linda, ils se lavent les dents. Prompt description Blue and Linda they REFL wash the teeth 'Blue and Linda, they are washing the teeth.'

b. Blue et Linda, que font- ils maintenant? Prompt question Blue and Linda what do they now 'Blue and Linda, what are they doing now?'

c. Blue, il lit un livre. Linda, elle parle au téléphone. Target description Blue he reads a book Linda she speaks to-the telephone 'Blue, he is reading a book. Linda, she is speaking on the phone.'

In the NP+VP condition, the picture sets differed slightly in order to de-emphasise the notion of establishing a topical contrast between the two referents. When the NP+VP construction was elicited, the prompt picture introduced two animals/characters involved in the same activity by using a NP+VP construction (7.a). The prompt description was followed by a prompt question in which the two subject NPs were repeated (7.b), the child was then presented with two successive target pictures in which the two referents were presented individually. The rationale for the separate presentation of the two referents was to set up a context that would optimally require the use of NP+VP in French.

(7) a. Le zèbre et le lion courent. Prompt description the zebra and the lion run 'The zebra and the lion run.' 
b. Que font le zèbre et le lion maintenant? Prompt question what do the zebra and the lion now

'What are the zebra and the lion doing now?'

c. Le zèbre boit de la limonade. Le lion joue au foot. Target description the zebra drinks some the lemonade the lion plays at-the football 'The zebra is drinking lemonade. The lion is playing football.'

The English materials followed the same pattern as the French materials in their use of LDs and NP+VP prompt descriptions and in the pragmatic contexts of the target pictures, although the actual picture stimuli were different as they were taken from stories that were different from the French set. We used different materials to avoid a practice effect across languages as the bilingual children were tested over two consecutive days (see the Appendix for a full list of experimental sentences in French and in English).

Crucially, LDs were used in the prompt descriptions to depict contrastive topics in English, a linguistic choice that was deliberately pragmatically sub-optimal. The rationale for this input manipulation was to test whether French-English bilingual children, who have both LDs and NP+VP structures available for topicality marking (i.e. LDs in French and NP+VP in English), would be more likely than monolingual English-speaking children to re-use LDs in their own description of contrastive topics.

\section{Procedure}

In both the French and the English experiment, elicitation condition (NP+VP; LD) was manipulated within subjects, and language exposure was treated as a continuous predictor. Half of the bilingual children took part in the French experiment first; the language of the experiment (French, English) and elicitation condition presentation order (NP+VP 
first; LD first) were counterbalanced throughout the experiments in order to diminish possible carry-over effects. For each study, the children were tested on consecutive school days with a different elicitation condition on each day (e.g. day 1: NP+VP day 2: LD). Children were seen individually on school premises and verbal consent to take part was obtained by the experimenter; only children whose parents had previously given their consent in writing were asked to participate. The children were told that they would play a game with the computer where they would take turns with the computer at describing pictures. They would have to listen to a prompt description of a picture (i.e. PowerPoint slide) that was audio-recorded by native-speakers of French and English before describing the second picture themselves. At the beginning of each testing session, the first author demonstrated the aim of the game in a practice item where she listened to the pre-recorded sentences and then proceeded to describe a target picture by way of example. Each testing-condition lasted no longer than 10 minutes; the sessions were audio-recorded for transcription and coding purposes.

\section{Coding}

Children's responses were transcribed and coded by the first author, a native speaker of French and advanced speaker of English. Target responses were coded as NP+VP (e.g. The zebra is dancing), LD (e.g. Velma, she is eating two biscuits), Pronoun+Verb (e.g. He is eating a cake) and Other (e.g. 0 calling somebody). Subject-less utterances and expletives (i.e. il $y$ a/there is) were classified as Other and were included in the analyses. Utterances with missing participles or complements such as in Alex is (holding) an umbrella or Woody, he is looking in the (toy box) were included as valid responses.

In order to examine the effect of elicitation condition, we then categorized each response as either being an instance of LD (1) or not (0). 


\section{Results}

Analyses were conducted using the lme4 package in R 3.0.2 (Bates, Maechler, Bolker, \& Walker, 2013; R Core Team, 2013). For each experiment, we conducted a Generalized Linear Mixed Model (GLMM) fit by maximum likelihood in order to examine the probability of producing a $\mathrm{LD}$ as a function of elicitation condition and to investigate the role of language exposure on the probability of producing a LD. We treated LD production as the dependent variable; elicitation condition and exposure to English were treated as fixed factors; the intercept, the elicitation condition, and their correlation were allowed to vary randomly by participants. Elicitation conditions varied within participants and exposure to English varied between participants. We centred the exposure to English predictor in order to avoid collinearity; 50\% corresponding to hypothetical 'perfectly' balanced bilingual.

Consequently, $-50 \%$ corresponded to English monolinguals while $+50 \%$ corresponded to French monolinguals. The model included both elicitation condition and exposure to English as fixed effects.

\section{Experiment 1: French results}

Figures 1 and 2 report the proportion of responses of LDs in the NP+VP and LD conditions respectively. The figures indicate that monolingual and bilingual children used a considerable number of LDs in both elicitation conditions. Bilingual children tended to produce fewer LDs than monolinguals. In the LD condition, monolinguals used LDs 64\% (232/360) of the time while the French dominant children produced LDs 57\% (126/220) of the time, balanced bilinguals 43\% (154/360) and English dominant only 39\% (55/140). A similar pattern is observed in the NP+VP condition. Monolinguals used LDs 56\% (202/360) of the time against 50\% (111/220) for the French dominant bilinguals, 27\% (96/360) for the 
balanced bilinguals and 36\% (51/140) for the English dominant bilinguals. These findings suggest that French monolingual children are more likely to use LDs than bilinguals regardless of the elicitation condition. Moreover, LD production is affected by the children's language background and by the amount of exposure to English.

$<$ Insert Figures 1 and 2 about here $>$

The GLMM indicated that all children were more likely to use a dislocation as a function of input manipulation in French $(\beta=1.59, \operatorname{SE}(\beta)=0.44, z=3.56, p<.001)$. The children were 4.90 times $\left(\mathrm{e}^{1.59}\right)$ more likely to produce a LD in the description of the target after hearing a LD in the prompt description. The analysis also showed a main effect of exposure to French on $\mathrm{LD}$ production $(\beta=0.05, \mathrm{SE}(\beta)=0.02, \mathrm{z}=2.95, p=.003)$ confirming that the use of LDs in French varies as a function of language exposure. For every percentage point increase in exposure to French, the likelihood of producing a LD rose by $1.05\left(\mathrm{e}^{0.05}\right)$. This result implies that reduced input to LDs in French made the participants less likely to use this construction. Finally, there was no interaction between elicitation condition and exposure to English suggesting that participants with more exposure to French were simply more likely to produce LDs regardless of context.

$<$ Insert Table 2 about here $>$

\section{Discussion}

All children produced significantly more LDs in the LD condition than in the NP+VP condition regardless of their language background. Although LDs were also very frequent in the NP+VP condition, the analysis reported that LDs were significantly more frequent in the 
LD condition. LDs were successfully elicited as a function of discourse-context and input manipulation when topics were identified by a LD in the prompt description and question. More interestingly in terms of potential CLI, LD production varied as a function of language exposure. For every additional point of exposure to French, the likelihood of producing a LD increased. Hence, the routine processing of LDs in French affected the children's likelihood of producing this construction. Children exposed to reduced French input were less likely to use LDs in discourse-pragmatically optimal contexts. In fact, the bilingual children used a considerable percentage of NP+VP structures, which corresponds to the English preferred structure. These findings lend support to the role of input quantity on children's use of pragmatically optimal syntactic constructions. The data show that the choice of grammatical structures was directly related to bilingual children's exposure to their two languages.

\section{Experiment 2: English results}

Figures 3 and 4 summarize the participants' responses in the NP+VP and LD condition respectively. In the LD condition, the English monolingual children did not produce any LDs, unlike the bilingual children who did use some LDs in this condition. The English dominant group produced LDs only $1 \%(1 / 140)$ of the time against $3 \%$ of the time for the balanced bilinguals (9/340). The French dominant children appeared to be the most responsive to the LD condition as they produced LDs $11 \%(24 / 220)$ of the time. In the NP+VP condition, LDs were largely absent in the children's elicited descriptions; English monolinguals used a trivial number of LDs $(0 \%-1 / 400)$ while the three groups of bilinguals produced LDs $1 \%$ of the time (i.e. English dominant: 1/140; balanced: 3/340; French dominant: 2/220). As in the French experiment, these findings indicate that the use of LDs is, at least partly, mediated by the bilinguals' language experience and relative exposure to French. 
$<$ Insert Figures 3 and 4 about here $>$

The GLMM showed no significant main effect on the likelihood of producing a LD as a function of elicitation condition $(\beta=-0.05, \mathrm{SE}(\beta)=0.58, \mathrm{z}=0.08, p=.93)$ despite the fact that the balanced and French dominant bilinguals used a non-negligible number of LDs in the LD condition. The analysis also indicated a significant effect of exposure to English on LD production $(\beta=-0.03, \mathrm{SE}(\beta)=0.01, \mathrm{z}=-2.56, p=.011)$ across all participants. For every percentage point increase in exposure to English, the likelihood of producing a LD decreased by $0.97\left(\mathrm{e}^{-0.03}\right)$. There was a marginal interaction between LD production and exposure to English $(\beta=-0.04, \operatorname{SE}(\beta)=0.02, \mathrm{z}=-1.86, \mathrm{p}=.063)$ suggesting that exposure to English made the participants less likely to use a LD in general. This implies that the greater the exposure to French the higher the likelihood that children would use a LD.

$<$ Insert Table 3 about here $>$

Discussion

In English, monolingual and bilingual children did not produce significantly more LDs after hearing a LD than a NP+VP. Despite the lack of a significant main effect of elicitation condition, language exposure affected the likelihood of producing LDs. Children with more exposure to English were less likely to produce LDs; this is unsurprising for monolingual children, but has interesting implications for bilingual children. The less a French-English bilingual child is exposed to English, and hence the more she is exposed to French, the more likely she is to use LDs. The fact that the children with the largest exposure to French were more likely to use LDs in English is consistent with the hypothesis that the 
likelihood and magnitude of CLI is affected, at least partly, by the input. Despite LDs being optimal to mark topicality in French only, French dominant children's use of LDs in English after hearing a pragmatically sub-optimal LD indicates that bilingual children's sensitivity to discourse-pragmatic appropriateness at the sentence level can be skewed by exposure to suboptimal structures in the input.

These results imply that input quality, i.e. possible exposure to an attrited or nonnative form of input resulting from potential CLI, may have important implications for bilingual children's acquisition and use of grammatical constructions. Exposure to contactmodified input may lead bilingual children to use certain optimal structures less frequently due to a lack of regular exposure to them and to resort to less discourse-pragmatically appropriate constructions, in this case LD to mark topicality in English.

\section{General discussion}

The overall aim of the present studies was to make a contribution to the current understanding of the role of processing mechanisms, discourse context, and language exposure on the phenomenon of CLI in sentential contexts. We investigated the expression of topicality in French and English in the wider framework of sentence-level constructions, thus taking the study of CLI beyond the level of individual referential expressions. We used an elicitation task to address the issue of syntactic choice in child bilingual speakers; specifically we explored the extent to which exposure to constructions where the mapping between syntax and discourse-pragmatics is sub-optimal, affects children's own uptake and production of these constructions. Finally, we considered the role of input in two different ways: firstly by conducting two within-language experiments where we included constructions that replicated instances of attrited/non-native input that bilingual children may be exposed to; 
secondly, by estimating children's relative exposure to their two languages and factoring in this proxy for language dominance to predict the likelihood of LD use.

The first main finding is that, in French, both monolingual and bilingual children predominantly produced LDs, while in English LDs were very infrequent overall and nonexistent in the monolingual group. The obvious pattern emerging from these results is that the absolute frequency of the construction in the language matters. Although LDs are in principle available in both French and English, it is only in the former that they are used pervasively to mark topicality, therefore it does not come as a surprise that both monolingual and bilingual children should produce more LDs in French than in English. This finding is yet another confirmation that the actual frequency of a construction in the input matters when it comes to language use.

Although in French there was a significant effect of elicitation condition, a somewhat unexpected finding was the substantial proportion of LDs even when the prompt descriptions included a NP+VP construction and the experimental contexts did not explicitly call for a topical contrast requiring a LD. A potential explanation for the children's behaviour in this condition is that our stimulus presentation may not have been as pragmatically felicitous as we intended it to be. Although we did only use NP+VP structures in the prompt descriptions and questions and we presented the two referents in separate and subsequent target pictures, it appears that the children did not view this context as sufficiently different from that of the LD elicitation condition in which the referents were presented side by side in one single target picture and were preceded by two LDs.

The second main finding is that, despite the non-trivial proportion of LDs after $\mathrm{NP}+\mathrm{VP}$ primes, the effect of elicitation condition was significant in French. In English we did not find such a main effect. Although there were some LDs produced after LD prompt descriptions and no LDs produced after NP+VP prompt descriptions, overall the number was 
too small to be significant. During the course of the English experiment, 20 presentations of LD constructions alongside 20 presentations of NP+VP constructions were not sufficient to skew the production of LDs. Taken at face value this suggests two things; firstly, that the children in our study were sensitive to the overall frequency of LDs in the English input, which we can assume to be very low, at least in the case of the English monolingual children. Secondly, and more interestingly, this result suggests that, aside from the low frequency of LD constructions, the fact that they are pragmatically sub-optimal in English is likely to have contributed to the monolingual children's resistance to use LDs. Some studies that have used the syntactic priming paradigm rather than just an elicitation study, as was the case here, have indeed shown that the likelihood of priming can be modulated by the semantic appropriateness of the primed construction (Messenger, Branigan, McLean, \& Sorace, 2012; Skarabela \& Serratrice, 2009). Our finding in an elicitation task suggests that discoursepragmatic appropriateness is also a mediator of the likelihood of syntactic choice.

The third result, and the one that is key to the argument being made here for the role of language processing, discourse context and language exposure on CLI, is that bilingual French-English children were sensitive to the elicitation condition and the likelihood of producing a LD after hearing a LD increased as a function of their language exposure. The more French the children were exposed to, the higher the chance that they would use a LD in contexts in which a monolingual would use a NP+VP construction. We interpret this instance of CLI to reflect the shared nature of syntactic representations in bilingual children and the probabilistic nature of the CLI phenomenon that is at least partly determined by the overall frequency of the construction in the input, and by the relative frequency of the input at the individual level. Although the analyses treated language exposure as a linear predictor, there is some reason to question the notion of a continuous linear relationship between input and performance in bilinguals (Paradis et al., 2011; Thordardottir, 2011; Hoff et al., 
2012). Previous investigations suggest that input quantity may only matter up to a critical point where the behaviour of bilinguals begins to match that of monolinguals. While the present study provides clear evidence for the direction of the relationship between input and performance, it remains an important question for future research to explore in more detail the function that maps input to output.

With regard to language processing, a growing body of research has started to consider the role of this variable on CLI (Nicoladis, 2006; Nicoladis, 2012; Nicoladis et al., 2010; Pirvulescu et al., 2012; Serratrice et al., 2009; Serratrice et al., 2011; Sorace et al., 2009). The theoretical motivation comes from research on bilingual adults showing that processing considerations have real implications for bilinguals' language use (Bernolet, Hartsuiker \& Pickering, 2007; Desmet \& Declercq, 2006; Hartsuiker \& Pickering, 2008; Hartsuiker et al., 2004; Schoonbaert et al., 2007). These studies suggested that bilingual adults share syntactic representations across languages, and recent experiments demonstrated that bilingual children would also have a shared syntax for structures that exist in their two languages as well as for those which are only present in one (Vasilyeva et al. 2010; Hsin et al. 2013). The present elicitation studies provide additional evidence that the mental representation of syntactic structures is affected by the simultaneous acquisition of two languages. The bilingual children's use of discourse-pragmatic sub-optimal LD constructions in English to mark topicality demonstrates that LDs were activated in these children's English to a significantly larger degree than for monolinguals; more interestingly, even within the bilingual group, the amount of exposure to French was critical in determining the likelihood of CLI. Complementary evidence from the French experiment also indicates that the bilingual children used more sub-optimal constructions (NP+VP) to mark topicality in French than their monolingual peers. 
We used a within-language set up where we presented the children with both optimal (in French) and sub-optimal (in English) form-meaning pairings to mark topicality. The rationale for this choice was to replicate the kind of attrited/non-native input that bilingual children might be exposed to. The assumption that bilingual children's input is only quantitatively different from monolinguals' is likely to be only partially correct; bilingual children are likely to have parents who are themselves non-native or attrited bilingual speakers and this will make their input different from a qualitative point of view too. In essence, a French-English bilingual child whose parents are either L2 or attrited speakers of English with French as their other language is likely to hear LDs in English in contexts in which a monolingual English-speaking adult would use a NP+VP construction. So exposure to these pragmatically sub-optimal LDs in English, alongside the routine exposure to pragmatically appropriate LDs in French, would boost the activation of LDs as topicality markers and increase the chances that they would be used in English more than would be reasonable to expect in the case of a monolingual child. The daily processing of high frequency structures such as LDs in French, and the shared syntactic representation of the form, strengthened by a potentially contact-modified English input exhibiting higher LD rates than in native English may reinforce the entrenchment of LDs across languages and thus lead to CLI. Conversely, the opposite effect may be observed with the potential entrenchment of NP+VP constructions in French to mark topicality when exposed to a contact-modified input resulting from prolonged exposure to English as a majority language. These findings show that input manipulation does play a role on the activation of grammatical constructions, in essence it increases the likelihood of CLI that we know is likely to take place when syntactic structures. The assumption that cross-linguistic activation is possible of course rests on the idea that bilinguals do share syntactic representation for isomorphic constructions (Serratrice 
et al., 2011); an idea that has been proposed in the adult bilingual psycholinguistic literature and that is starting to gain traction in the child bilingual literature too.

Our finding of an effect of language dominance on CLI is in line with recent work showing that the magnitude of CLI varies as a function of the bilingual children's exposure to their languages (Argyri \& Sorace, 2007; Serratrice et al., 2009; Serratrice et al., 2011). Unlike in previous studies where language dominance was not measured for individual children but language of the community was used as a proxy, our results provide a quantifiable measure of the probability to produce a LD as a function of language exposure at the individual level. These findings suggest that dislocations are more or less accessible in French-English bilingual children's mental representations as a function of language exposure.

In conclusion, the present elicitation studies provide new evidence supporting the role of processing mechanisms on CLI. The existence of shared syntax across languages implies that processing high frequency structures in one language can lead to their entrenchment in bilinguals' other language, even when the discourse-context is not discourse-pragmatically optimal. Measuring language exposure at the level of the individual child we showed that the quantity of input matters for the likelihood of CLI; using a within-language experimental paradigm we showed that the quality of the input that is addressed to bilingual children also has a role to play and that non-native/attrited input may skew the activation of a syntactic structure even when it is not the best form-function fit. 
Eliciting dislocations in French-English bilingual children 31

References

Argyri, E., \& Sorace, A. (2007). Crosslinguistic influence and language dominance in older bilingual children. Bilingualism: Language and Cognition, 10(1), 79-99.

Barnes, \& Garcia, I. (2013). Vocabulary growth and composition in monolingual and bilingual Basque infants and toddlers. International Journal of Bilingualism, 17(3), $357-374$

Barnes, B. (1985). The Pragmatics of Left Detachment in Spoken Standard French. Amsterdam: John Benjamins.

Bates, D., Maechler, M., Bolker, B., \& Walker, S. (2013). Package 'lme4'.

Blasco-Dulbecco, M. (1999). Les dislocations en français contemporain. Paris: Champion.

Blom, E. (2010). Effects of input on the early grammatical development of bilingual children. International Journal of Bilingualism, 14, 422-446.

Bock, J. K. (1986). Syntactic persistence in language production. Cognitive psychology, $18(3), 355-387$.

Branigan, H. (2007). Syntactic priming. Language and Linguistics Compass, 1(1 $\square 2)$, 1-16.

Cattani, A., Abbot-Smith, K., Farag, R., Krott, A., Arreckx, F., Dennis, I., \& Foccia, C.

(2014). How much exposure to English is necessary for a bilingual toddler to perform like a monolingual peer in language tests? International Journal of Language \& Communication Disorders.

De Cat, C. (2002). French dislocations: PhD dissertation, University of York.

De Cat, C. (2009). Experimental Evidence for Preschoolers' Mastery of "Topic”. Language Acquisition, 16(4), 224-239.

Delais-Roussarie, E., Doetjes, J., \& Sleeman, P. (2004). Dislocation. In F. Corblin \& H. de Swart (Eds.), Handbook of French semantics (pp. 501-528). Stanford: CSLI. 
Desmet, T., \& Declercq, M. (2006). Cross-linguistic priming of syntactic hierarchical configuration information. Journal of Memory and Language, 54(4), 610-632.

Donaldson, B. (2011). Left-dislocation in near-native French. Studies in Second Language Acquisition, 33(3), 399-432.

Döpke, S. (1998). Competing language structures: The acquisition of verb placement by bilingual German-English children. Journal of Child Language, 25(3), 555-584.

Foroodi-Nejad, F., \& Paradis, J. (2009). Crosslinguistic transfer in the acquisition of compound words in Persian-English bilinguals. Bilingualism: Language and Cognition, 12(04), 411-427.

Gathercole, V.C.M. \& Hoff, E. (2007). Input and the acquisition of language: Three questions. In E. Hoff \& M. Shatz (eds), Blackwell handbook of language development, 107-127. Oxford: Blackwell Publishing.

Geluykens, R. (1992). From discourse process to grammatical construction: on left dislocation in English. Amsterdam/Philadelphia: John Benjamins.

Gregory, M. L., \& Michaelis, L. A. (2001). Topicalization and left-dislocation: A functional opposition revisited. Journal of pragmatics, 33(11), 1665-1706.

Hacohen, A., \& Schaeffer, J. (2007). Subject realization in early Hebrew/English bilingual acquisition: The role of crosslinguistic influence. Bilingualism: Language and Cognition, 10(3), 333.

Hartsuiker, R. J., Pickering, M. J., \& Veltkamp, E. (2004). Is syntax separate or shared between languages? Cross-linguistic syntactic priming in Spanish-English bilinguals. Psychological Science, 15(6), 409-414.

Hauser-Grüdl, N., Arencibia Guerra, L., Witzmann, F., Leray, E., \& Müller, N. (2010). Cross-linguistic influence in bilingual children: Can input frequency account for it? Lingua, 120(11), 2638-2650. 
Hervé, C. (2014). French-English bilingual children's encoding of old and new information: $\mathrm{PhD}$ dissertation, University of Manchester.

Hoff, E., Core, C., Place, S., Rumiche, R., Senor, M., \& Parra, M. (2012). Dual language exposure and early bilingual development. Journal of Child Language, 39(1), 1-27.

Hsin, L., Legendre, G., \& Omaki, A. (2013). Priming cross-linguistic interference in Spanish-English bilingual children. Paper presented at the Proceedings of the 37th Annual Boston University Conference on Language Development.

Hulk, A., \& Müller, N. (2000). Bilingual first language acquisition at the interface between syntax and pragmatics. Bilingualism: Language and Cognition, 3(03), 227-244.

Kidd, E. (2012). Individual differences in syntactic priming in language acquisition. Applied Psycholinguistics, 33(2), 393-418.

Kidd, E., Chan, A., \& Chiu, J. (2014). Cross-linguistic influence in simultaneous CantoneseEnglish bilingual children's comprehension of relative clauses. Bilingualism: Language and Cognition,

Kupisch, T. (2007). Determiners in bilingual German-Italian children: What they tell us about the relation between language influence and language dominance. Bilingualism: Language and Cognition, 10(1), 57-78.

Lambrecht, K. (1981). Topic, Antitopic and Verb Agreement in Non-Standard French. Amsterdam: John Benjamins.

Lambrecht, K. (2001). Dislocation. In M. Haspelmath, E. König, W. Oesterreicher, \& W. Raible (Eds.), Language Typology and Language Universals: An International Handbook. (pp. 1050-1078). Berlin/New York: Walter de Gruyter.

Loebell, H., \& Bock, K. (2003). Structural priming across languages. Linguistics, 41(5), 791824. 
Marchman, V. A. \& Martinez-Sussmann, D. (2002). Concurrent validity of caregiver/parent report measure of language for children who are learning both English and Spanish. Journal of Speech, Language, and Hearing Research 45, 983-97.

Marchman, V.A., Martinez-Sussmann, C. \& Dale, P.S. (2004). The language-specific nature of grammatical development: Evidence from bilingual language learners. Developmental Science 7, 212-24.

Messenger, K., Branigan, H. P., McLean, J. F., \& Sorace, A. (2012). Is young children’s passive syntax semantically constrained? Evidence from syntactic priming. Journal of Memory and Language, 66(4), 568-587.

Nicoladis, E. (2006). Cross-linguistic transfer in adjective-noun strings by preschool bilingual children. Bilingualism: Language and Cognition, 9(1), 15-32.

Nicoladis, E. (2012). Cross-linguistic influence in French-English bilingual children's possessive constructions. Bilingualism: Language and Cognition, 15(2), 320-328.

Nicoladis, E., \& Paradis, J. (2011). Learning to liaise and elide comme il faut: evidence from bilingual children. Journal of Child Language, 38(4), 701-730.

Nicoladis, E., Rose, A., \& Foursha-Stevenson, C. (2010). Thinking for speaking and crosslinguistic transfer in preschool bilingual children. International Journal of Bilingual Education and Bilingualism, 13(3), 345-370.

Notley, A., van der Linden, E., \& Hulk, A. (2007). Cross-linguistic influence in bilingual children: the case of dislocation. In S. Baauw, F. Drijkoningen, \& M. Pinto (Eds.), Romance Languages and Linguistic Theory (pp. 229-258). Amsterdam: John Benjamins.

Ochs-Keenan, E., \& Schieffelin, B. (1976). Foregrounding referents: a reconsideration of left dislocation in discourse Proceedings of Annual Meeting of the Berkeley Linguistics Society (Vol. 2, pp. 240-257). 
Paradis, J. (2011). Individual differences in child English second language acquisition: Comparing child-internal and child-external factors. Linguistic Approaches to Bilingualism, 1(3), 213-237.

Paradis, J., \& Navarro, S. (2003). Subject realization and crosslinguistic interference in the bilingual acquisition of Spanish and English: what is the role of the input? Journal of Child Language, 30(2), 371-393.

Paradis, J., Nicoladis, E., Crago, M., \& Genesee, F. (2011). Bilingual children's acquisition of the past tense: A usage-based approach. Journal of Child Language, 38(3), 554-578.

Patterson, J. (2002). Relationships of expressive vocabulary to frequency of reading and television experience among bilingual toddlers. Applied Psycholinguistics, 23, 493508.

Pinto, M. (2006). Subject pronouns in bilinguals. The acquisition of syntax in Romance languages, 41, 331-350.

Pirvulescu, M., Pérez-Leroux, A., \& Roberge, Y. (2012). A bidirectional study of object omissions in French-English bilinguals. In K. Braunmüller \& C. Gabriel (Eds.), Multilingual Individuals and Multilingual Societies (pp. 171-188). Amsterdam: John Benjamins.

Prince, E. (1981). Toward a taxonomy of given-new information. In P. Cole (Ed.), Radical pragmatics (pp. 223-255). New York: New York Academic Press.

Savage, C., Lieven, E., Theakston, A., \& Tomasello, M. (2003). Testing the abstractness of children's linguistic representations: Lexical and structural priming of syntactic constructions in young children. Developmental Science, 6(5), 557-567.

Savage, C., Lieven, E., Theakston, A., \& Tomasello, M. (2006). Structural priming as implicit learning in language acquisition: The persistence of lexical and structural priming in 4-year-olds. Language Learning and Development, 2(1), 27-49. 
Schmid, M. S. (2010). Languages at play: The relevance of L1 attrition to the study of bilingualism. Bilingualism: Language and Cognition, 13(1), 1-7.

Schoonbaert, S., Hartsuiker, R. J., \& Pickering, M. J. (2007). The representation of lexical and syntactic information in bilinguals: Evidence from syntactic priming. Journal of Memory and Language, 56(2), 153-171.

Serratrice, L. (2007). Cross-linguistic influence in the interpretation of anaphoric and cataphoric pronouns in English-Italian bilingual children. Bilingualism: Language and Cognition, 10(3), 225-238.

Serratrice, L. (2013). Cross-linguistic influence in bilingual development: Determinants and mechanisms. Linguistic Approaches to Bilingualism, 3(1), 3-25.

Serratrice, L., Sorace, A., Filiaci, F., \& Baldo, M. (2009). Bilingual children's sensitivity to specificity and genericity: Evidence from metalinguistic awareness. Bilingualism: Language and Cognition, 12(2), 239-257.

Serratrice, L., Sorace, A., Filiaci, F., \& Baldo, M. (2011). Pronominal objects in EnglishItalian and Spanish-Italian bilingual children. Applied Psycholinguistics, 33(4), 725.

Serratrice, L., Sorace, A., \& Paoli, S. (2004). Crosslinguistic influence at the syntaxpragmatics interface: Subjects and objects in English-Italian bilingual and monolingual acquisition. Bilingualism: Language and Cognition, 7(3), 183-206.

Shimpi, P. M., Gámez, P. B., Huttenlocher, J., \& Vasilyeva, M. (2007). Syntactic priming in 3-and 4-year-old children: Evidence for abstract representations of transitive and dative forms. Developmental Psychology, 43(6), 1334.

Skarabela, B., \& Serratrice, L. (2009). 'The doctor's mother' or 'the mother of the doctor'?: Syntactic priming of possessive noun phrases in English preschoolers Online Supplement of the Proceedings of the 33rd BUCLD. 
Smithson, L., Paradis, J., \& Nicoladis, E. (2014). Bilingualism and receptive vocabulary achievement: Could sociocultural context make a difference?. Bilingualism: Language and Cognition, 17(4), 810-821.

Snider, N., \& Zaenen, A. (2006). Animacy and syntactic structure: Fronted NPs in English. Intelligent Linguistic Architectures: Variations on Themes by Ronald M. Kaplan. CSLI Publications, Stanford.

Sorace, A., \& Serratrice, L. (2009). Internal and external interfaces in bilingual language development: Beyond structural overlap. International Journal of Bilingualism, 13(2), 195-210.

Sorace, A., Serratrice, L., Filiaci, F., \& Baldo, M. (2009). Discourse conditions on subject pronoun realization: Testing the linguistic intuitions of older bilingual children. Lingua, 119(3), 460-477.

Sundara, M., \& Scutellaro, A. (2011). Rhythmic distance between languages affects the development of speech perception in bilingual infants. Journal of Phonetics, 39(4), 505-513.

Team, R. C. (2013). R: A language and environment for statistical computing. R Foundation for Statistical Computing, Vienna, Austria.

Thordardottir, E. (2011). The relationship between bilingual exposure and vocabulary development. International Journal of Bilingualism, 15(4), 426-445.

Thothathiri, M., \& Snedeker, J. (2008). Give and take: Syntactic priming during spoken language comprehension. Cognition, 108(1), 51-68.

Tsimpli, I., Sorace, A., Heycock, C., \& Filiaci, F. (2004). First language attrition and syntactic subjects: A study of Greek and Italian near-native speakers of English. International Journal of Bilingualism, 8(3), 257-277. 
Unsworth, S. (2013). Assessing the role of current and cumulative exposure in simultaneous bilingual acquisition: The case of Dutch gender. Bilingualism: Language and Cognition, 16(01), 86-110.

Unsworth, S. (2014). Amount of exposure as a proxy for dominance in bilingual language acquisition. In C. Silva-Corvalán \& J. Treffers-Daller (Eds.), Language dominance in bilinguals: Issues of measurement and operationalization. Cambridge: Cambridge University Press.

Vasilyeva, M., Waterfall, H., Gamez, P. B., Gomez, L. E., Bowers, E., \& Shimpi, P. (2010). Cross-linguistic syntactic priming in bilingual children. Journal of Child Language, $37(5), 1047$. 
Eliciting dislocations in French-English bilingual children 39

Table 1. Bilinguals' exposure to French and English.

\begin{tabular}{lcc}
\hline Language exposure & Paris bilinguals & London bilinguals \\
\hline Dominant in French $(\operatorname{Exp}>60 \%)$ & 2 & 9 \\
Balanced $(60 \%>\operatorname{Exp}>40 \%)$ & 13 & 6 \\
Dominant in English $(\operatorname{Exp}<40 \%)$ & 3 & - \\
NA & 1 & 19 \\
Total & 19 & \\
\hline
\end{tabular}


Table 2. Model coefficients (in logits) for the likelihood of producing a LD in French.

\begin{tabular}{lllllll}
\hline Fixed Effect & Estimate & SE & $\mathbf{z}$ & $\operatorname{Pr}(>|\mathbf{z}|)$ & Random Effect & Variance \\
\hline Analysis & & & & & & \\
Intercept & -1.73897 & 0.56699 & -3.07 & $0.00216^{* *}$ & Intercept & 10.10 \\
Elicit & & & & & & \\
condition & 1.59193 & 0.44718 & 3.56 & $0.00037^{* * *}$ & Elicit condition & 3.65 \\
ExpEng & 0.04872 & 0.01650 & 2.95 & $0.00315^{* *}$ & & \\
Elicit vs. & & & & & & \\
ExpEng & -0.00772 & 0.01268 & -0.61 & 0.54267 & & \\
& & & & & & \\
\end{tabular}


Eliciting dislocations in French-English bilingual children 41

Table 3. Model coefficients (in logits) for the likelihood of producing a LD in English.

\begin{tabular}{lllllll}
\hline Fixed Effect & Estimate & $\mathbf{S E}$ & $\mathbf{z}$ & $\operatorname{Pr}(>|\mathbf{z}|)$ & Random Effect & Variance \\
\hline Analysis & & & & & & \\
Intercept & -4.7646 & 0.2898 & -16.44 & $<2 \mathrm{e}-16^{* * *}$ & Intercept & 0.886 \\
Elicit & & & & & & \\
condition & -0.0480 & 0.5826 & -0.08 & 0.934 & Elicit condition & 3.709 \\
ExpEng & -0.0278 & 0.0109 & -2.56 & $0.011^{*}$ & & \\
Elicit vs. & & & & & & \\
ExpEng & -0.0406 & 0.0218 & -1.86 & 0.063 & & \\
\end{tabular}

1 The experimenter's prompts in English and French were pre-recorded by a female native speaker of French and a female native speaker of English to ensure consistency of presentation across all participants. 


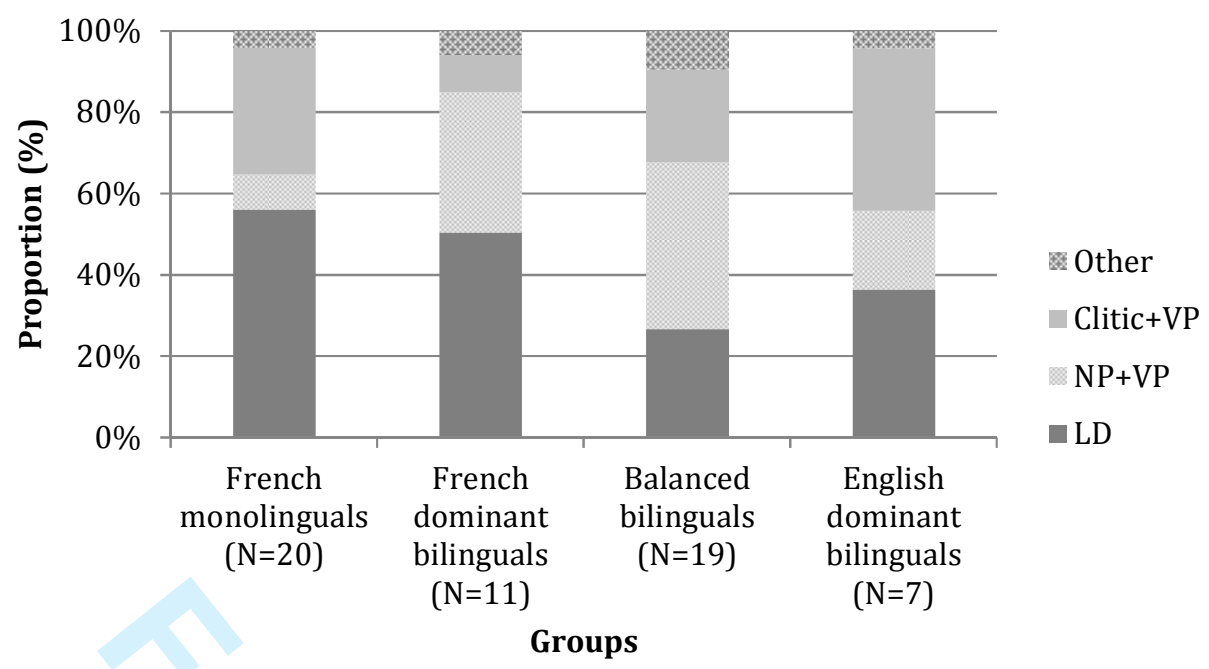

Figure 1. Proportion of responses in the NP+VP condition in French. 


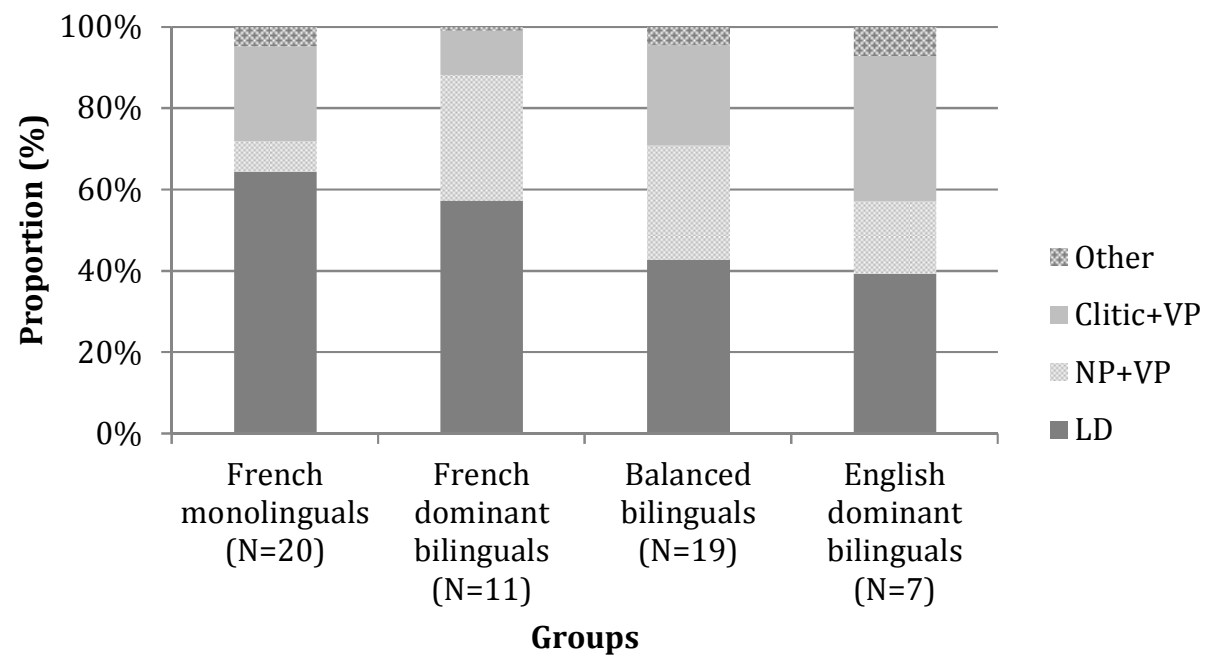

Figure 2. Proportion of responses in the LD condition in French. 


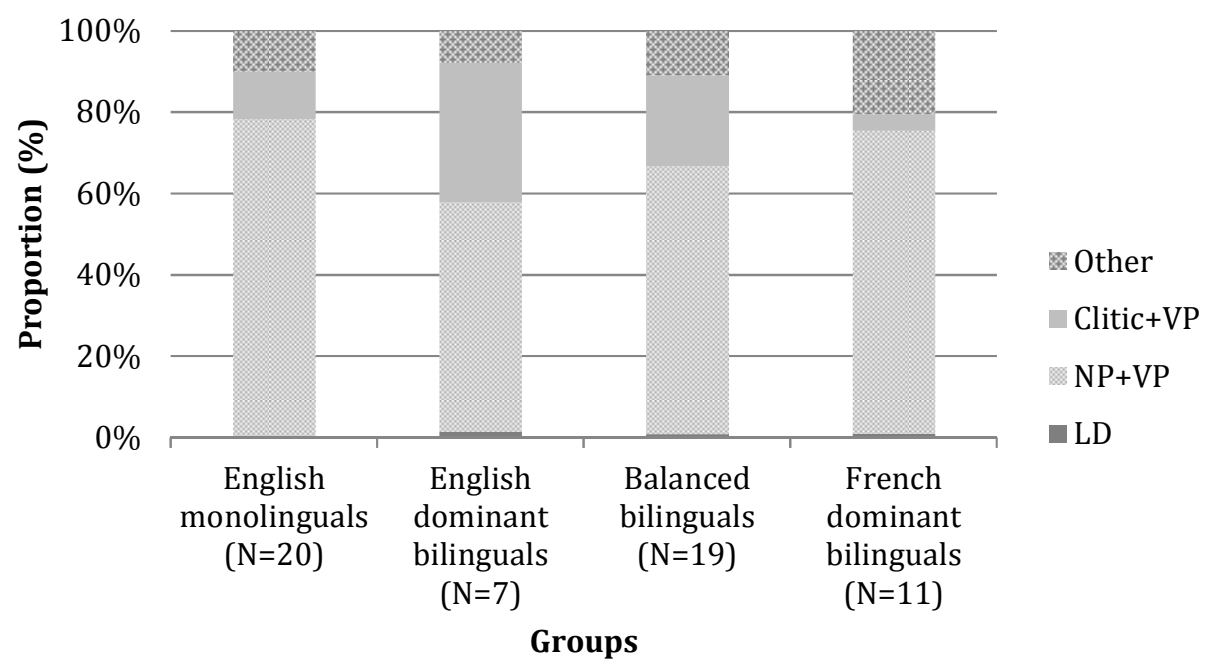

Figure 3. Proportion of responses in the NP+VP condition in English. 


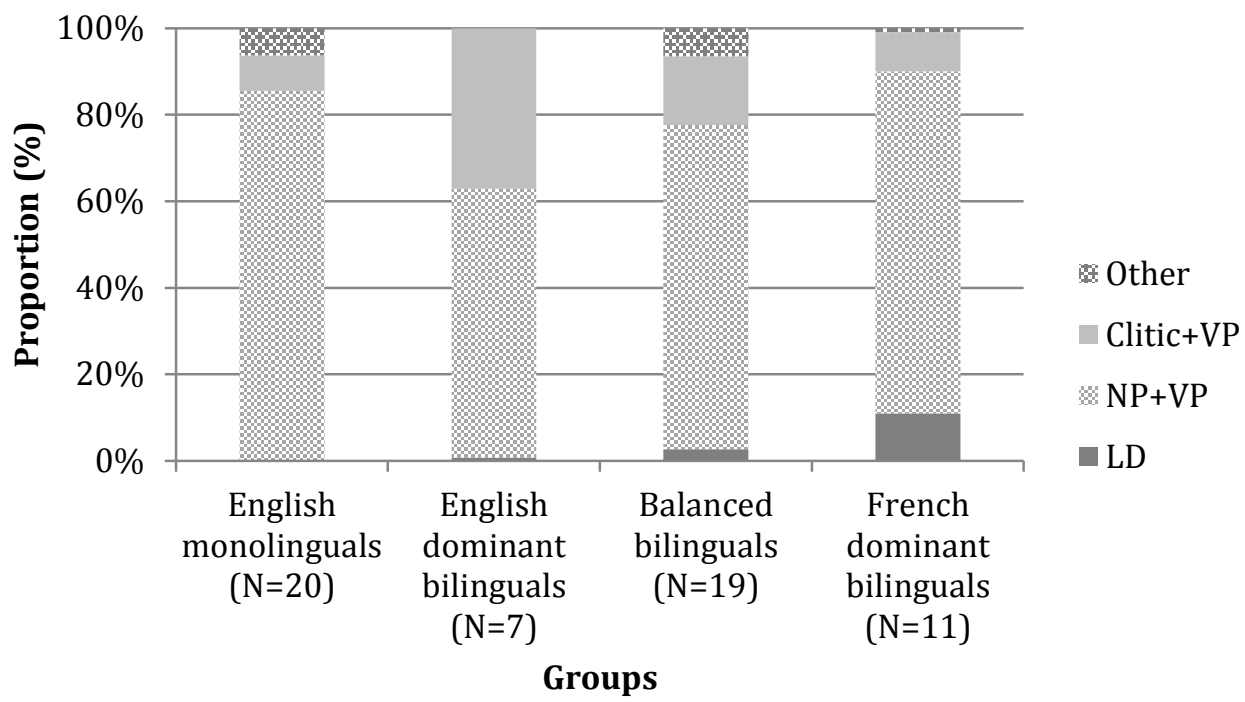

Figure 4. Proportion of responses in the LD condition in English. 